cholinergic activity may also contribute to the observed reactions.

Until clinical operational criteria for diagnosing senile dementia of Lewy body type are validated it is not possible to predict accurately which of the growing number of confused and demented elderly patients may be at increased risk of neuroleptic sensitivity. Probably a significant minority of patients with senile dementia of Lewy body type will erroneously meet currently accepted criteria for a diagnosis of possible Alzheimer's disease and in others there will be a misdiagnosis of vascular dementia. A preliminary evaluation of the proposed clinical criteria for senile dementia of Lewy body type (box) in a mixed population of demented patients indicates a sensitivity of $85 \%$ and a specificity of $96 \%$, with neuropathological diagnosis as the validating criterion (McKeith et al, unpublished data).

Acute confusion and fluctuating cognitive impairment with associated hallucinations and delusions without an identifiable underlying cause typifies some, but not all, presentations of senile dementia of Lewy body type. Patients will potentially be seen in accident and emergency departments; medical, geriatric, and psychogeriatric clinics; and in general practice. A degree of caution may be advised in prescrib- ing neuroleptics for these patients, and if sudden deterioration occurs in such circumstances the possibility of the neuroleptic sensitivity syndrome associated with senile dementia of Lewy body type should be considered. Increased morbidity and mortality are associated with such reactions, the management of which may be similar to that of the neuroleptic malignant syndrome.

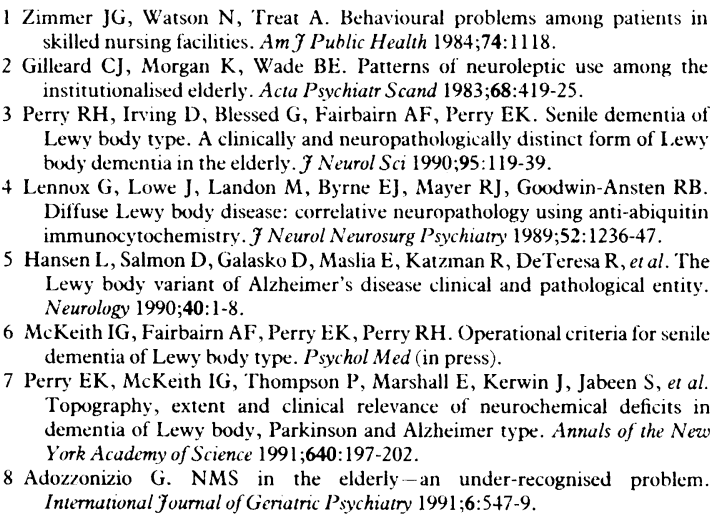

6 McKeith IG, Fairbairn AF, Perry EK, Perry RH. Operational criteria for senile dementia of Lewy body type. Psychol Med (in press).

7 Perry EK, McKeith IG, Thompson P, Marshall E, Kerwin J, Jabeen S, et al. Topography, extent and clinical relevance of neurochemical deficits in dementia of Lewy body, Parkinson and Alzheimer type. Annals of the New York Academy of Science 1991;640:197-202.

8 Adozzonizio G. NMS in the elderly-an under-recognised problem. International Joumal of Geriatric Psychiatry 1991;6:547-9.

Diabetic Retinopathy Unit, Department of Medicine, Royal Postgraduate Medical School,

Hammersmith Hospital, London W12 0NN

Vinod Patel, fuvenile

Diabetes Federation

postdoctoral fellow

Salwan Rassam, clinical

research fellow

Richard Newsom, clinical research fellow

Jutta Wiek, clinical research fellow

Eva Kohner, professor of medical ophthalmology

Correspondence to: Professor Kohner.

\title{
Retinal blood flow in diabetic retinopathy
}

\author{
Vinod Patel, Salwan Rassam, Richard Newsom, Jutta Wiek, Eva Kohner
}

\section{Abstract}

Objectives - $(a)$ To report on the basic parameters of retinal blood flow in a population of diabetic patients with and without retinopathy and nondiabetic controls; (b) to formulate a haemodynamic model for the pathogenesis of diabetic retinopathy from this and other studies.

Design-Laser-Doppler velocimetry and computerised image analysis to determine retinal blood flow in a large cross sectional study.

Setting-Diabetic retinopathy outpatient clinic.

Subjects -24 non-diabetic controls and 76 diabetic subjects were studied (63 patients with insulin dependent diabetes, 13 with non-insulin dependent diabetes). Of the diabetic subjects, 12 had no diabetic retinopathy, 27 had background retinopathy, 13 had pre-proliferative retinopathy, 12 had proliferative retinopathy, and 12 had had pan-retinal photocoagulation for proliferative retinopathy.

Main outcome measures-Retinal blood flow $(\mu \mathrm{l} / \mathrm{min})$ and conductance (rate of flow per unit of perfusion pressure).

Results-In comparison with non-diabetic controls $(9.52 \mu \mathrm{l} / \mathrm{min})$ and diabetic patients with no diabetic retinopathy $(9 \cdot 12 \mu \mathrm{l} / \mathrm{min})$ retinal blood flow was significantly increased in all grades of untreated diabetic retinopathy (background $12 \cdot 13 \mu \mathrm{l} / \mathrm{min}$, preproliferative $15.27 \mu \mathrm{l} / \mathrm{min}$, proliferative 13.88 $\mu \mathrm{l} / \mathrm{min})$. There was a significant decrease in flow after pan-retinal photocoagulation in comparison with all the other groups studied $(4.48 \mu \mathrm{l} / \mathrm{min})$. Conductance of the retinal circulation was higher in the untreated diabetic retinopathy groups. These results were independent of age, sex, type of diabetes, duration of diabetes, glycated haemoglobin concentration, blood glucose concentration, blood pressure, and intraocular pressure.

Conclusions-Retinal blood flow is significantly increased in diabetic retinopathy in comparison with non-diabetic controls and diabetic subjects with no retinopathy. This has implications for controlling hypertension and hyperglycaemia as a strategy in reducing morbidity from diabetic retinopathy.

\section{Introduction}

Diabetic retinopathy remains an important public health concern. In the most definitive epidemiological study to date the yearly incidence of blindness due to diabetes mellitus was found to be 3.3 per 100000 population, or around 1600 cases for England and Wales.' Despite intensive research effort the pathogenic mechanisms important to the initiation and progression of diabetic retinopathy are still poorly understood. It is clear that whatever humoral factors influence the microcirculation it remains to be explained why it is the retina that develops capillary occlusion, exudates, microaneurysms, haemorrhages, and new vessel formation whereas other microcirculations do not. The other important site of microangiopathic insult is the kidney. There the pathogenic mechanisms are becoming clearer as it has become apparent that hyperperfusion of the glomerulus is central to the progression of diabetic glomerulonephropathy. ${ }^{2}$ With the introduction of the laser-Doppler velocimeter developed by Riva $e t$ al it has been possible to measure the velocity of the blood flow in large retinal vessels objectively, reproducibly, and non-invasively. ${ }^{3}$ This together with the determination of vessel diameters by computerised image analysis has allowed a precision in the study of the parameters of retinal blood flow not hitherto possible. We present our study of the haemodynamic changes in diabetic retinopathy in a cross sectional population of diabetic patients.

\section{Subjects and methods}

Twenty four non-diabetic subjects and 76 diabetic patients were investigated (see table I). The nondiabetics were recruited from the departmental staff 
and accompanying persons of the diabetic patients attending the diabetic retinopathy clinic. The diabetic patients were recruited from the diabetic retinopathy clinic. All diabetic patients aged $16-70$ years and with no ocular disease other than diabetic retinopathy, normal intraocular pressure, visual acuity $6 / 12$ or better, and stable glycaemic control as assessed by their haemoglobin $A_{1}$ values were asked to join the study. Six diabetic subjects had to be excluded because of their inability to fixate on the laser-Doppler velocimeter target.

Sample size calculations indicated that approximately 10 subjects would be required in each of the retinopathy groups in order to detect a statistically significant difference in retinal blood flow of $20 \%$ with a power of $95 \%$ at the $5 \%$ significance level. This level of difference may be expected from similar work with different methodologies. ${ }^{4}$ It was therefore decided at the outset to continue recruitment until a minimum of 12 subjects were recruited into each group. The diabetic patients had routine clinical examination and full ophthalmological examination, including intraocular pressure measurement, direct and indirect ophthalmoscopy, and slit lamp biomicroscopy with a fundus lens. They were graded with respect to their retinopathy from five field stereo colour photographs by two observers using the Hammersmith grading system. ${ }^{5}$ The absence of retinopathy in the no retinopathy group was confirmed by fluorescein angiography.

Background retinopathy was defined as the presence of microaneurysms, exudates, and haemorrhages. Preproliferative retinopathy was characterised by background retinopathy lesions and two or more of the following: venous beading or reduplication, or both; intraretinal microvascular abnormalities; clusters of deep retinal haemorrhages; and multiple cotton wool spots. Patients with proliferative diabetic retinopathy were shown to have new vessel formation on photographs and fluorescein angiography. Those in the post-panretinal photocoagulation group had had a minimum of 1500 burns of laser photocoagulation for proliferative diabetic retinopathy and were at the time of flow measurement free of new vessels. Of the 76 diabetic subjects studied, 12 had no retinopathy, 27 had background retinopathy, 13 had pre-proliferative retinopathy, 12 had proliferative retinopathy, and 12 had had pan-retinal photocoagulation. The diabetic population consisted of 63 insulin dependent and 13 non-insulin dependent patients. All subjects in this study gave informed consent after a detailed explanation. The experimental design was approved by the local ethical committee in accordance with the principles of the Declaration of Helsinki.

On arrival at the diabetic retinopathy unit patients had their blood pressure determined in the sitting position, the average of three readings at least two minutes apart being used. Systolic and diastolic blood pressures were recorded at phases 1 and 5 of the Korotkoff sounds, respectively. Subjects then had their visual acuity and refraction measured. Pupillary dilatation was achieved with tropicamide $1 \%$ eye drops. Thereafter, laser-Doppler velocimetry (see below), retinal photography, and intraocular pressure measurement were undertaken. Diabetic subjects had venepuncture for haemoglobin $\mathrm{A}_{1}$ (affinity chromatography) and blood glucose determinations (glucose analyser II, Beckmann Instruments, California).

\section{RED CELL VELOCITY DETERMINATION}

The bidirectional laser-Doppler velocimeter (Oculix, Philadelphia) was used to determine red cell velocity in retinal veins. The velocimeter consists of a low power helium-neon laser (wavelength $632.8 \mathrm{~nm}$, irradiance $80 \mathrm{~mW} / \mathrm{cm}^{2}$ ) which can be focused on to a retinal vein via the illumination path of a Topcon
TRC-JE fundus camera (Topcon, Osaka, Japan). The laser light scattered by the moving red cells in the vessel is reflected back through the camera and collected on to two photomultipliers. The signal from these photomultipliers is analysed by a minicomputer (Masscomp, Massachusetts) and the maximal red cell velocity displayed. Complete details of the method have been published. ${ }^{36} \mathrm{With}$ the existing equipment it is only possible to measure red cell velocities in retinal veins. Previous studies have shown that retinal blood flow is similar in the superior and inferior temporal vessels and that the veins drain over $95 \%$ of their accompanying arteries, with the arterial flow very similar to the venous flow. ${ }^{7}$ Therefore, flow in a single temporal retinal vein is used as the determinant of retinal blood flow. ${ }^{8}$

The point of measurement in laser-Doppler velocimetry was usually the superior temporal vein, always within one disc diameter from the disc edge before any bifurcation. The raw data were stored on the hard disk of the computer identifiable only by the file number. Determination of velocity was made in masked fashion. The $95 \%$ confidence interval for reproducibility of laser-Doppler velocimetry has been found to be $8.9 \%$ to $-8 \cdot 9 \% .^{9}$

\section{VESSEL DIAMETER DETERMINATION}

Fundus photographs of the vein that had the velocity measurement were taken with a 30 degree fundus camera (Carl Zeiss, Oberkochen, Germany) using technical pan film (Kodak, Rochester, New York) and a $570 \mathrm{~nm}$ red free filter. The photographic negatives were transilluminated on a microscope stage and digitised by a video scanner on to a $512 \times 512$ screen by using an image analysis computer (Context Vision, Linköping, Sweden). Vessel diameter was determined from the average of three readings from three photographs by using the half height of the transmittance profile. ${ }^{10}$ Since the camera's magnification of the retina is dependent on the refraction status of the subject all vessel diameter measurements were corrected for the subject's refraction according to the tables of Bengtsson and Krakau." The coefficient of variation for this technique has been found to be $0 \cdot 26 \% .^{12}$

\section{CALCULATIONS}

Retinal blood flow-The laser-Doppler velocimeter allows measurement of the maximal centre line red cell velocity $\left(\mathrm{V}_{\max }\right)$. Dividing $\mathrm{V}_{\max }$ by 1.6 provides the mean red cell velocity according to Damon and Duling. ${ }^{13}$ Volumetric retinal blood flow was calculated from mean red cell velocity $\left(\mathrm{V}_{\text {mean }}\right)$ and vessel diameter (D) using the formula: retinal blood flow $(\mu \mathrm{l} / \mathrm{min})=$ $\left(\left(\pi . D^{2}\right) / 4\right) \times V_{\text {mean }}$. Retinal perfusion pressure was calculated by subtracting the intraocular pressure from two thirds of the mean arterial blood pressure. ${ }^{14}$

Conductance and resistance-The conductance of a circulation is used as a measure of its ability to allow blood flow through at a given perfusion pressure. Conductance $(\mu \mathrm{l} / \mathrm{min} / \mathrm{mm} \mathrm{Hg})$ is therefore retinal blood flow per unit of perfusion pressure and is calculated by dividing the volumetric retinal blood flow by the perfusion pressure. ${ }^{15}$ Before conductance is calculated for each of the study groups it is important to exclude subjects with any degree of hypertension since high perfusion pressure would result in autoregulation of the retinal vasculature tending to reduce retinal blood flow. The purpose of determining retinal conductance was to provide an index of retinal blood flow independently of any autoregulatory changes due to an increased perfusion pressure. Therefore, all subjects with a systolic blood pressure greater than $140 \mathrm{~mm} \mathrm{Hg}$ and diastolic blood pressure greater than $90 \mathrm{~mm} \mathrm{Hg}$ were excluded in accordance with the guidelines on hypertension in diabetes before calcu- 
lation of the conductance. ${ }^{16}$ The resistance of a circulation $(\mathrm{mm} \mathrm{Hg} / \mu \mathrm{l} / \mathrm{min})$ is its ability to resist flow. Its value is the reciprocal of the conductance. ${ }^{15}$

\section{STATISTICAL METHODS}

One way analysis of variance was used to define whether significant differences existed between the different groups with respect to the basic parameters of retinal blood flow. It was then that Student's $t$ test was used to test for the differences in each haemodynamic parameter for the retinopathy groups in comparison with non-diabetic controls and the no retinopathy diabetic group. One way analysis of variance together with a conservative multiple comparison test (Scheffe's test) was used for comparing differences in retinal blood flow between non-diabetic controls, no retinopathy group, untreated diabetic retinopathy (background, pre-proliferative, and proliferative), and pan-retinal photocoagulation groups. The effects of the possible confounding variables of age, sex, systolic blood pressure, diastolic blood pressure, mean arterial blood pressure, blood glucose concentration, haemoglobin $A_{1}$ value, intraocular pressure, and type and duration of diabetes mellitus on the parameters of retinal blood flow were determined by stepwise multiple linear regression multivariate analysis using Minitab data analysis software (Minitab Inc, 1989).

\section{Results}

A summary of the clinical data is shown in table I. The non-diabetic controls were significantly younger than the no retinopathy group $(p=0.03)$, pre-proliferative retinopathy group $(p<0.001)$, and the proliferative retinopathy subjects $(p=0 \cdot 003)$. There was no significant difference in ages between the diabetic groups. Systolic and diastolic blood pressures were significantly higher $(p<0.012)$ in all diabetic retinopathy groups when compared with the non-diabetic control group. With the exception of the proliferative retinopathy subjects, in whom diastolic blood pressure was higher than in the no retinopathy group $(p=0.01)$ there were no significant differences in systolic and diastolic blood pressures among the diabetic groups. The mean arterial pressure $(p<0.02)$ and perfusion pressure $(\mathrm{p}<0.003)$ were higher in the diabetic retinopathy groups when compared with the non-diabetic control subjects. The proliferative retinopathy mean arterial blood pressure $(p=0.016)$ and perfusion pressure $(p=0.017)$ were higher than in the no retinopathy group. No other significant differences in mean arterial

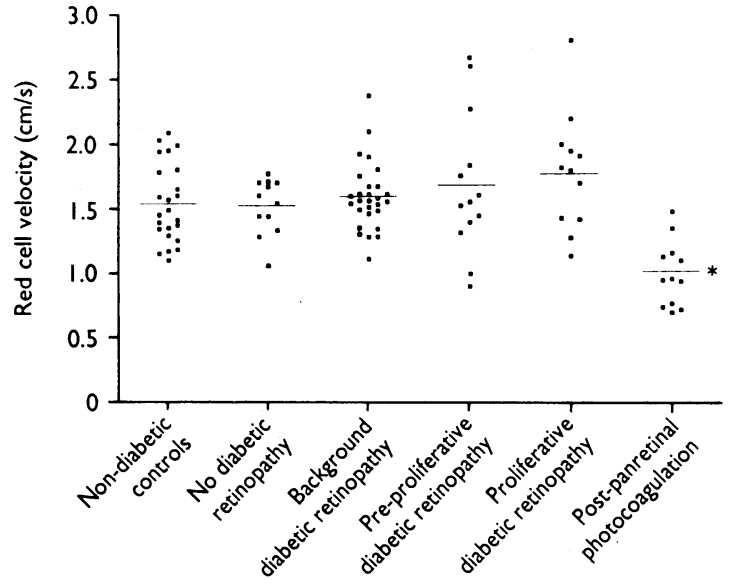

FIG 1-Maximum red cell velocity in study groups. Bars are means. ${ }^{\star} p<0.001$ Compared with all other groups

pressure and perfusion pressure were noted within the diabetic groups. There were no significant differences in intraocular pressure.

The clinical data pertinent to the diabetic subjects are summarised in table II. In comparison with the no retinopathy group there were no significant differences in duration of diabetes, haemoglobin $A_{1}$ value, and blood glucose concentration at the time of blood flow measurement.

Analysis of variance showed that there were intergroup differences in $\mathrm{V}_{\max }(F=11.95, \mathrm{p}<0.005, \mathrm{df}=3)$. Although there were no significant differences between the non-diabetic controls, no retinopathy group, and untreated retinopathy group, a trend for an increase in $\mathrm{V}_{\max }$ was noted with increasing severity of retinopathy (non-diabetic controls $1.53(\mathrm{SD} 0.30) \mathrm{cm} / \mathrm{s}$, no retinopathy group $1.49(0.22) \mathrm{cm} / \mathrm{s}$, background retinopathy group $1.57(0.27) \mathrm{cm} / \mathrm{s}$, pre-proliferative retinopathy group $1.67(0.55) \mathrm{cm} / \mathrm{s}$, proliferative retinopathy group $1.78(0.45) \mathrm{cm} / \mathrm{s})$. There was a highly significant decrease after pan-retinal photocoagulation (0.98 $(0.26) \mathrm{cm} / \mathrm{s}, \mathrm{p}<0.001)($ fig 1$)$.

The analysis of variance on the vein diameter data indicated significant intergroup differences $(F=15 \cdot 90$, $\mathrm{p}<0.005, \mathrm{df}=3$ ). Vein diameter was significantly larger in comparison with non-diabetic controls in all untreated retinopathy groups (non-diabetic controls 143.9 (SD 17.8) $\mu \mathrm{m}$, background retinopathy group $160.0(24.3) \mu \mathrm{m}(\mathrm{p}=0.03)$, pre-proliferative retinopathy group $174.8(17.7) \mu \mathrm{m}(\mathrm{p}<0.001)$, proliferative retinopathy group $162.6(21 \cdot 6) \mu \mathrm{m}(\mathrm{p}=0.03))$. Vein

TABLE I-Clinical characteristics of subjects. Except where stated otherwise, values are means $(S D)$

\begin{tabular}{|c|c|c|c|c|c|c|}
\hline & $\begin{array}{l}\text { Non-diabetic } \\
\text { controls }\end{array}$ & $\begin{array}{l}\text { No diabetic } \\
\text { retinopathy }\end{array}$ & $\begin{array}{c}\text { Background } \\
\text { diabetic } \\
\text { retinopathy }\end{array}$ & $\begin{array}{l}\text { Pre-proliferative } \\
\text { diabetic } \\
\text { retinopathy }\end{array}$ & $\begin{array}{c}\text { Proliferative } \\
\text { diabetic } \\
\text { retinopathy }\end{array}$ & $\begin{array}{l}\text { Post-panretinal } \\
\text { photocoagulation }\end{array}$ \\
\hline No & 24 & 12 & 27 & 13 & 12 & 12 \\
\hline$M: F$ & $16: 8$ & $10: 2$ & 19:8 & $10: 3$ & $6: 6$ & $10: 2$ \\
\hline Age (years) & $33 \cdot 0(5 \cdot 2)$ & $41 \cdot 6(7 \cdot 3)$ & $36 \cdot 3(11 \cdot 9)$ & $48 \cdot 5(12 \cdot 5)$ & $38 \cdot 4(12 \cdot 1)$ & $42 \cdot 6(12 \cdot 8)$ \\
\hline Systolic blood pressure $(\mathrm{mm} \mathrm{Hg})$ & $115 \cdot 8(14 \cdot 0)$ & $127 \cdot 7(22 \cdot 0)$ & $131 \cdot 2(23.9)$ & $139.5(25.0)$ & $145 \cdot 2(23.4)$ & $128 \cdot 8(13 \cdot 0)$ \\
\hline Diastolic blood pressure $(\mathrm{mm} \mathrm{Hg})$ & $70 \cdot 6(9 \cdot 0)$ & $74.6(9 \cdot 9)$ & $78.9(13.0)$ & $84 \cdot 3(14 \cdot 0)$ & $86.5(11.5)$ & $86.9(8 \cdot 7)$ \\
\hline Mean arterial pressure $(\mathrm{mm} \mathrm{Hg})$ & $85 \cdot 7(10 \cdot 0)$ & $92 \cdot 3(12 \cdot 4)$ & $96.6(15.9)$ & $102 \cdot 7(17 \cdot 1)$ & $106 \cdot 1(13 \cdot 6)$ & $94 \cdot 2(9 \cdot 2)$ \\
\hline Intraocular pressure $(\mathrm{mm} \mathrm{Hg})$ & $16 \cdot 7(2 \cdot 7)$ & $17 \cdot 3(3 \cdot 5)$ & $16 \cdot 4(3 \cdot 3)$ & $15 \cdot 8(3 \cdot 2)$ & $16 \cdot 6(2.4)$ & $14.9(2.5)$ \\
\hline Perfusion pressure $(\mathrm{mm} \mathrm{Hg}$ ) & $40 \cdot 3(7 \cdot 0)$ & $44 \cdot 1(9 \cdot 4)$ & $46 \cdot 8(9 \cdot 8)$ & $52.6(11.9)$ & $54 \cdot 8(9 \cdot 4)$ & $48 \cdot 3 \cdot(5 \cdot 5)$ \\
\hline
\end{tabular}

Statistically significant differences are given in Results.

TABLE II-Clinical characteristics of diabetic subjects. Except where stated otherwise values are means (SD)

\begin{tabular}{|c|c|c|c|c|c|}
\hline & $\begin{array}{l}\text { No diabetic } \\
\text { retinopathy }\end{array}$ & $\begin{array}{l}\text { Background } \\
\text { diabetic } \\
\text { retinopathy }\end{array}$ & $\begin{array}{l}\text { Pre-proliferative } \\
\text { diabetic } \\
\text { retinopathy }\end{array}$ & $\begin{array}{l}\text { Proliferative } \\
\text { diabetic } \\
\text { retinopathy }\end{array}$ & $\begin{array}{l}\text { Post-panretinal } \\
\text { photocoagulation }\end{array}$ \\
\hline $\begin{array}{l}\text { No with insulin dependent diabetes: No with non-insulin } \\
\text { dependent diabetes } \\
\text { Mean duration (years) (interquartile range) } \\
\text { Haemoglobin } A_{1}(\%) \\
\text { Plasma glucose }(\mathrm{mmo} / \mathrm{l})\end{array}$ & $\begin{array}{l}10: 2 \\
13 \cdot 1(9-12) \\
9 \cdot 0(3 \cdot 0) \\
10 \cdot 2(5 \cdot 1)\end{array}$ & $\begin{array}{l}25: 2 \\
16 \cdot 5(11-21) \\
9 \cdot 0(2 \cdot 2) \\
10 \cdot 0(5 \cdot 3)\end{array}$ & $\begin{array}{c}8: 5 \\
13 \cdot 5(2-20) \\
9 \cdot 8(2 \cdot 5) \\
11 \cdot 1(4 \cdot 2)\end{array}$ & $\begin{array}{l}10: 2 \\
16 \cdot 4(11-22) \\
9 \cdot 9(2 \cdot 8) \\
12 \cdot 5(4 \cdot 5)\end{array}$ & $\begin{array}{l}10: 2 \\
24 \cdot 3(22-26) \\
9 \cdot 1(1 \cdot 9) \\
12 \cdot 5(6 \cdot 3)\end{array}$ \\
\hline
\end{tabular}

Statistically significant differences are given in Results. 
diameter was not significantly different between nondiabetic controls and the no retinopathy group (no retinopathy group $140.6(25 \cdot 2) \mu \mathrm{m})$ but was significantly smaller in the post-panretinal photocoagulation group in comparison with all the other groups studied $(122.3(15.9) \mu \mathrm{m}, \mathrm{p}<0.05)$ (fig 2)

There was no significant difference in retinal blood flow between non-diabetic controls and the no retinopathy group $(9.52$ (SD $3 \cdot 18) \mu \mathrm{l} / \mathrm{min}$ and $9 \cdot 12$ (3.83) $\mu \mathrm{l} / \mathrm{min}$ respectively). Analysis of variance showed that significant intergroup differences existed $(F=18 \cdot 21, \mathrm{p}<0.005, \mathrm{df}=3)$; in comparison with nondiabetic controls retinal blood flow was significantly higher in all the untreated retinopathy groups (background retinopathy $12.13(3.92) \mu \mathrm{l} / \mathrm{min}$, pre-proliferative retinopathy $15.27(5.88) \mu \mathrm{l} / \mathrm{min}$, proliferative retinopathy $13.88 \quad(4.51) \mu \mathrm{l} / \mathrm{min}$; Scheffe's test $\left.\mathrm{L} / \mathrm{SE}(\mathrm{L})=3.67, \quad V\left\{(\mathrm{k}-1) F_{0.005}\right\}=2 \cdot 23, \quad \mathrm{p}=0 \cdot 005\right)$. Furthermore, retinal blood flow was significantly higher in the untreated retinopathy groups in comparison with the no retinopathy subjects (Scheffe's test $\left.\mathrm{L} / \mathrm{SE}(\mathrm{L})=3 \cdot 26, \quad V\left\{(\mathrm{k}-1) F_{0.025}\right\}=3 \cdot 17, \quad \mathrm{p}=0.025\right)$ After pan-retinal photocoagulation retinal blood flow was considerably lower in comparison with all the other groups studied $(4.48(1.89) \mu \mathrm{l} / \mathrm{min}$; Scheffe's test $v$ non-diabetic controls $\mathrm{L} / \mathrm{SE}(\mathrm{L})=3.535$, $\bigvee\left\{(\mathrm{k}-1) F_{0.01}\right\}=2 \cdot 877, \mathrm{p}=0.01 ; v$ no retinopathy group $\mathrm{L} / \mathrm{SE}(\mathrm{L})=2 \cdot 829, \quad \vee\left\{(\mathrm{k}-1) F_{0.05}\right\}=2 \cdot 877$, $\mathrm{p}=0 \cdot 06 ; v$ untreated retinopathy group $\mathrm{L} / \mathrm{SE}(\mathrm{L})=6 \cdot 867$, $\left.\vee\left\{(\mathrm{k}-1) F_{0.005}\right\}=3.767, \mathrm{p}<0.005\right)($ fig 3$)$.

The data on retinal blood flow, perfusion pressure, conductance, and resistance in subjects with blood pressure less than $140 / 90 \mathrm{~mm} \mathrm{Hg}$ are shown in table III. Retinal blood flow was significantly increased in all the untreated retinopathy groups when compared with non-diabetic controls and the no retinopathy group $(p<0 \cdot 023)$ with a significant decrease after pan-retinal photocoagulation $(p<0 \cdot 001)$. Conductance of the retinal circulation was higher in the untreated retinopathy groups than in the non-diabetic controls and

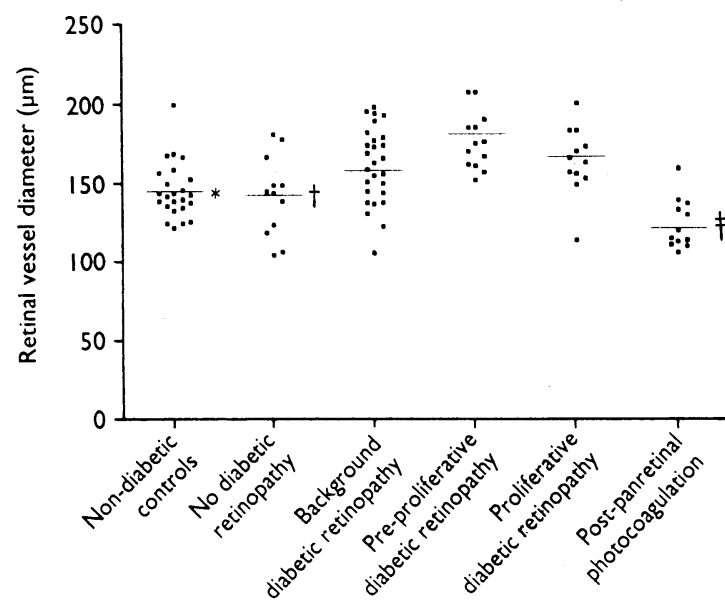

FIG 2-Retinal vessel diameter in study groups. Bars are means. ${ }^{\star} p<0.03$ Compared with background diabetic retinopathy, preproliferative diabetic retinopathy, and proliferative diabetic retinopathy. $t p<0.05$ Compared with background diabetic retinopathy and pre-proliferative diabetic retinopathy. $\neq p<0.05$ Compared with all other groups

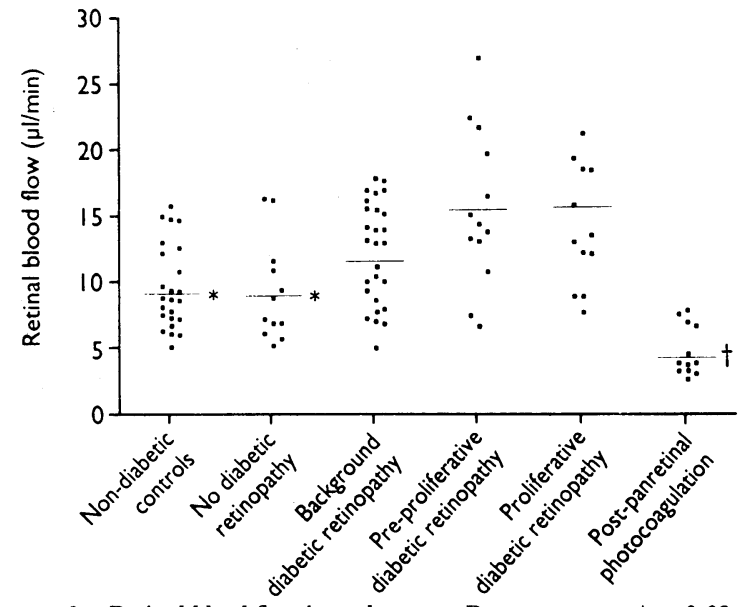

FIG 3-Retinal blood flow in study group. Bars are means. ${ }^{\star} p<0.03$ Compared with background diabetic retinopathy, pre-proliferative diabetic retinopathy, and proliferative diabetic retinopathy. $t_{p}<0.001$ Compared with all other groups

no retinopathy group (compared with non-diabetic controls: background retinopathy group $\mathrm{p}<0.05$, preproliferative retinopathy group $\mathrm{p}=0.06$, proliferative retinopathy group $\mathrm{p}<0 \cdot 001$; compared with no retinopathy group: background retinopathy group $p<0.05$, pre-proliferative retinopathy group $p=0.06$, proliferative retinopathy group $\mathrm{p}<0 \cdot 001)$. There was no significant difference in conductance between non-diabetic controls and the no retinopathy group. Conductance was significantly lower after pan-retinal photocoagulation when compared with any of the other groups $(p<0.01)$. The significance of the changes in resistance paralleled the changes in conductance as described above.

The above intergroup differences in the parameters of retinal blood flow were found to be independent of the possible confounding variables of age, sex, systolic blood pressure, diastolic blood pressure, mean arterial blood pressure, blood glucose concentration, haemoglobin $A_{1}$ value, intraocular pressure, and type and duration of diabetes mellitus using multivariate analysis.

\section{Discussion}

This study showed hyperperfusion in the diabetic retinal circulation in all groups of untreated diabetic retinopathy in comparison with non-diabetic controls and diabetic patients with no retinopathy. In comparison with diabetic subjects with no retinopathy retinal blood flow was higher by $33.2 \%$ in background, $69.4 \%$ in pre-proliferative, and $50.1 \%$ in proliferative diabetic retinopathy. The observation that the conductance of the retinal circulation was increased in diabetic retinopathy shows that there is hyperperfusion even when the systemic blood pressure and ocular perfusion pressure are normal. Interestingly, there was a significant reduction in retinal blood flow and conductance after pan-retinal photocoagulation.

Other studies using the mean circulation time of fluorescein have also suggested an increase in retinal blood flow in diabetic retinopathy. ${ }^{47}$ Grunwald et al

TABLE III-Blood flow, conductance, and resistance in retinal circulation of normotensive subjects. Except where stated otherwise values are means $(S D)$

\begin{tabular}{|c|c|c|c|c|c|c|}
\hline & $\begin{array}{l}\text { Non-diabetic } \\
\text { controls }\end{array}$ & $\begin{array}{l}\text { No diabetic } \\
\text { retinopathy }\end{array}$ & $\begin{array}{l}\text { Background } \\
\text { diabetic } \\
\text { retinopathy }\end{array}$ & $\begin{array}{l}\text { Pre-proliferative } \\
\text { diabetic } \\
\text { retinopathy }\end{array}$ & $\begin{array}{l}\text { Proliferative } \\
\text { diabetic } \\
\text { retinopathy }\end{array}$ & $\begin{array}{l}\text { Post-panretinal } \\
\text { photocoagulation }\end{array}$ \\
\hline $\begin{array}{l}\text { No } \\
\text { Flow }(\mu \mathrm{l} / \mathrm{min}) \\
\text { Perfusion pressure }(\mathrm{mm} \mathrm{Hg}) \\
\text { Conductance }(\mu \mathrm{l} / \mathrm{min} / \mathrm{mm} \mathrm{Hg}) \\
\text { Resistance }(\mathrm{mm} \mathrm{Hg} / \mu \mathrm{l} / \mathrm{min})\end{array}$ & $\begin{array}{c}22 \\
9 \cdot 30(3 \cdot 10) \\
38 \cdot 4(5 \cdot 2) \\
0 \cdot 246(0 \cdot 09) \\
4 \cdot 06(1 \cdot 45)\end{array}$ & $\begin{array}{l}9 \\
8 \cdot 96(3 \cdot 39) \\
41 \cdot 2(9 \cdot 0) \\
0 \cdot 222(0.072) \\
4 \cdot 50(1 \cdot 47)\end{array}$ & $\begin{array}{l}19 \\
12 \cdot 97(3 \cdot 92) \\
43 \cdot 1(4 \cdot 4) \\
0 \cdot 306(0 \cdot 105) \\
3 \cdot 27(1 \cdot 13)\end{array}$ & $\begin{array}{l}\quad 9 \\
15 \cdot 01(6 \cdot 39) \\
45 \cdot 7 \cdot(4 \cdot 8) \\
0 \cdot 331(0 \cdot 147) \\
3 \cdot 02(1 \cdot 35)\end{array}$ & $\begin{array}{l}6 \\
15 \cdot 97(4 \cdot 51) \\
47 \cdot 1(7 \cdot 1) \\
0 \cdot 342(0 \cdot 096) \\
2 \cdot 92(0 \cdot 54)\end{array}$ & $\begin{array}{c}10 \\
4 \cdot 02(1 \cdot 71) \\
46 \cdot 9(5 \cdot 7) \\
0 \cdot 086(0 \cdot 032) \\
12 \cdot 05(4 \cdot 43)\end{array}$ \\
\hline
\end{tabular}

Statistically significant differences are given in Results. 
using laser-Doppler velocimetry showed no significant changes in retinal blood flow in diabetic retinopathy, though a non-significant increase in retinal blood flow of $16.0 \%$ in background diabetic retinopathy was noted. ${ }^{8}$ The explanation may lie in the fact that the study by Grunwald $e t$ al was smaller, and also vessel diameters were determined by manual projection micrometry. The computerised image analysis technique used in our study is less prone to observer error. ${ }^{18}$ In a recent study by Grunwald's group retinal blood flow was found to be increased significantly in diabetic patients with mild background retinopathy and poor glycaemic control in comparison with control subjects. ${ }^{19}$ The percentage increase in retinal blood flow was $23 \cdot 4 \%$, which is comparable to that in our background retinopathy group.

MODEL

We have attempted a synthesis of the present state of knowledge of the retinal circulation in diabetes and formulated a simple model of how hyperperfusion and

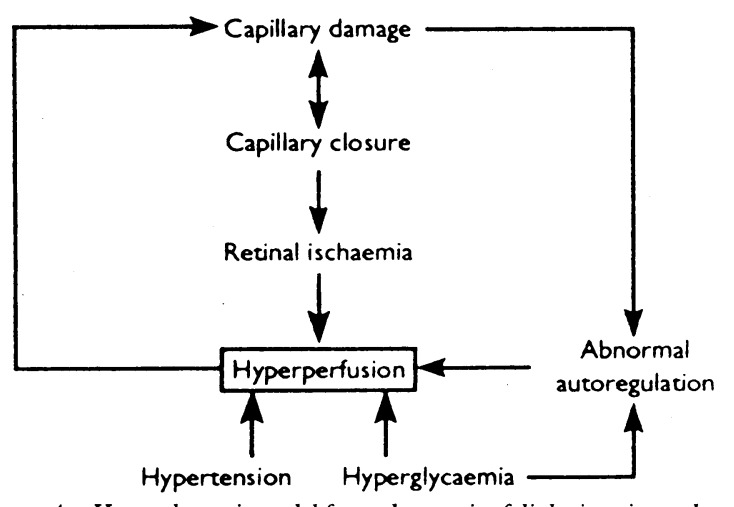

FIG 4-Haemodynamic model for pathogenesis of diabetic retinopathy

abnormal autoregulation may lead to the progression of diabetic retinopathy (fig 4). The earliest changes in diabetic retinopathy are thickening of the basement membrane and pericyte loss. Pericytes are very important in the regulation of blood flow since they possess contractile properties allowing changes in the vessel lumen to regulate blood flow. ${ }^{2021}$ At the capillary level in diabetes there is increased blood viscosity, decreased red cell deformability, and increased platelet aggregation. ${ }^{22} 23$ These lead to decreased capillary blood flow and even thrombosis in the smallest vessels of the retinal circulation. It is worth noting that both aspirin and ticlopidine reduce the rate of microaneurysm formation in early retinopathy, which could be attributed to the platelet inhibitory antithrombotic effect of these drugs. ${ }^{24} 25$

The overall effect of basement membrane thickening, decreased capillary perfusion, and the biochemical effects of hyperglycaemia is capillary closure. The resultant retinal ischaemia is a potent stimulus for an increase in retinal blood flow; indeed, areas of dilated capillaries in areas adjacent to capillary drop out are often seen in fluorescein angiography. It is thought that retinal ischaemia leading to the production of angiogenic and vasoproliferative factors is the main stimulus for new vessel formation. ${ }^{26}$ The increase in flow at the edge of the area of capillary closure results in an increment in shear stress to the vessel wall ${ }^{27}$ as: wall shear stress $=(4 \eta \mathrm{Q}) /\left(\pi R^{3}\right)$, where $\eta=$ viscosity, $Q=$ volume flow, $R=$ radius.

The relations in this equation help us to understand one of the mechanisms behind capillary damage in diabetes. Increased flow, increased viscosity, and capillary closure - all of which occur in diabetes - tend to increase shear stress. Injury to the endothelium of a vessel can result from an increase in shear stress alone. ${ }^{28}$ Tooke postulated that increased glycation and thickening of the basement membrane results in "locking" of the vessel. ${ }^{29}$ This would tend to increase shear stress since the vessel diameter is unable to change.

Hyperperfusion is also associated with increased capillary pressure since the systemic blood pressure is more easily transmitted to the microcirculation in the presence of dilated vasculature. The circumferential stress in a vessel is directly proportional to the perfusion pressure and radius of the vessel and inversely proportional to the thickness of the vessel wall. ${ }^{30}$ It is conceivable that in larger vessels of the retinal circulation there is circumferential stress damage to the vessel wall and a continuing propensity to dilatation. Since the tension in a wall resisting the distension pressure in a vessel is inversely proportional to the radius (Laplace's law) an increase in wall tension is required to counterbalance the distending pressure in a dilated vessel. ${ }^{27}$ The required wall tension is not attained so there is a propensity towards dilatation with subsequent hyperperfusion. The capillary hypertension and shear stress changes will also result in a net increase in fluid leaving the retinal capillaries (Starling's forces); this would contribute to retinal oedema, especially as there is no lymphatic circulation to drain away the excess interstitial fluid. ${ }^{15}$ This is then manifested by retinal exudates and oedema leading, in the macular area, to diabetic maculopathy.

There is evidence of abnormal autoregulation of the retinal circulation in diabetes which can lead to hyperperfusion. ${ }^{31-33}$ The increased conductance may be due to the autoregulatory response of the retinal circulation to retinal ischaemia; indeed, the conductance increases with the degree of ischaemia. Another explanation is that the retinal circulation in diabetic retinopathy is abnormally regulating to a normal perfusion pressure leading to hyperperfusion. Both hyperglycaemia and hypertension lead to hyperperfusion in the retinal circulation..$^{34} 35$

Although it is clear from this study that there is a relation between increasing severity of retinopathy and hyperperfusion in the retinal circulation, it is difficult to ascertain whether this reflects a pathogenic mechanism or a covariable in association with increasing retinal ischaemia in the presence of a disturbed diabetic metabolism. The haemodynamic model proposed remains speculative since this study determined haemodynamic changes at a single point in time rather than prospectively. Tooke has formulated a model for microangiopathic damage in diabetes in which increased blood flow is important. ${ }^{29}$

\section{CLINICAL FACTORS}

Several clinical factors have been shown to influence the progression of diabetic retinopathy. Hypertension was found to be a significant risk factor for the incidence and progression of diabetic retinopathy in several studies ${ }^{36-38}$ In the study by Klein et al there was a significant relation between the incidence and progression of diabetic retinopathy and blood pressure in insulin dependent diabetic subjects; comparing the highest with the lowest quartile of systolic blood pressure, the relative risk ratios were 1.8 for the incidence of any retinopathy and 3.6 for progression to proliferative diabetic retinopathy. Pregnancy in diabetic patients is often associated with a deterioration in retinopathy. ${ }^{39}$ Recent work indicates that retinal blood flow is increased by $110 \%$ in diabetic pregnancies. ${ }^{40}$

Further evidence for hyperperfusion having an important aetiological role in the progression of diabetic retinopathy comes from the observations that raised intraocular pressure and unilateral carotid stenosis, both of which reduce retinal blood flow, tend to protect against diabetic retinopathy..$^{41+2} \mathrm{~A}$ similar 
situation occurs with respect to diabetic renal disease since renal artery stenosis protects against diabetic glomerulopathy. ${ }^{43}$ Brenner's original hypothesis that hyperperfusion of the glomerulus is important to the progression of diabetic nephropathy ${ }^{44}$ has in effect been validated as it has been shown that treatment of hypertension reduces the rate of decline of renal function..$^{45}$

In conclusion, hyperperfusion of the retinal circulation is present in diabetic retinopathy. The haemodynamic model proposes a central role for hyperperfusion in the pathogenesis of diabetic retinopathy. Since hypertension and hyperglycaemia cause hyperperfusion it is important to control these factors in the overall strategy to reduce the morbidity due to diabetic retinopathy.

We are grateful to Dr G Davies and Dr P Sullivan for the validation of the laser-Doppler velocimeter. This work was supproted by the British Diabetic Association through a group grant to Professor E M Kohner and a fellowship of the Juvenile Diabetes Foundation to Dr V Patel.

1 Moss SE, Klein R, Klein BEK. The incidence of vision loss in a diabetic population. Ophthalmology 1988;95:1340-8.

2 Parving HH, Viberti GC, Keen H, Christiansen JS, Lassen NA. Hemodynamic factors in the genesis of diabetic microangiopathy. Metabolism 1983;32: 943-9.

3 Riva CE, Grunwald JE, Sinclair SH, O'Keefe K. Fundus camera based retinal LDV. Applied Optics 1981;20:117-20.

4 Kohner EM, Hamilton AM, Saunders SJ, Sutcliffe BA, Bulpitt CJ. The retinal blood flow in diabetes. Diabetologia 1975;11:27-33.

5 Oakley N, Hill DW, Joplin G, Kohner EM, Russell Fraser T. Diabetic retinopathy. 1 . The assessment of severity and progress by comparison with a standard set of photographs. Diabetologia 1967;3:402-5.

6 Caldwell G, Davies EG, Sullivan PM, Morris AH, Kohner EM. A laser Doppler velocimetry study of the effect of hypoglycaemia on retinal blood Doppler velocimetry study of the effect of hypo
flow in the mini-pig. Diabetologia 1990;33:262-5.

7 Feke GT, Tagawa H, Deupree DM, Goger DG, Sebag J, Weiter JJ. Blood flow in the normal human retina. Invest Ophthalmol Vis Sci 1989;30:58-65.

8 Grunwald JE, Riva CE, Brucker AJ, Sinclair SH, Petrig BL. Laser Doppler velocimetry study of the retinal circulation in diabetes mellitus. Arch Ophthalmol 1986:104:991-6.

9 Sullivan P, Davis G, Kohner E. Methodology and reproducibility of bidirectional laser Doppler velocimetry. Folia Ophthalmologica 1990;15: 99-101.

10 Brinchmann HO, Engvold O. Microphotometry of the blood column and the light streak on retinal vessels in fundus photographs. Acta Ophthalmol (Copenh) 1986;95:861-8.

11 Bengtsson B, Krakau CET. Some essential optical features of the Zeiss fundus camera. Acta Ophthalmol (Copenh) 1977;55:123-31.

12 Chen HC, Wiek J, Rassam SMB, Patel V, Kohner EM. Retinal vessel diameter changes in the cardiac cycle [abstract]. Invest Ophthalmol Vis Sci 1992;33: 811 .

13 Damon DN, Duling BR. A comparison between mean blood velocities and centre-line red cell velocities as measured with a mechanical image streaking centre-line red cell velocities as measured wit
velocimeter. Microvasc Res 1979;17:330-2.

14 Strauss AL, Kedra AW. Experiences with a new procedure for the measurement of the ophthalmic artery pressure: ophthalmomanometry-Doppler. ment of the ophthalmic artery pressure:

15 Ross J, Schmid-Schoenbein G. Dynamics of the peripheral circulation. In: Best and Taylor's physiological basis of medical practice. Baltimore: Williams and Wilkins, 1990 : 138-58.

16 Working Group on Hypertension in Diabetes. Statement on hypertension in diabetes. Arch Intern Med 1987;147:830-42.

17 Cunha Vaz JG, Fonseca JR, de Abreu JRF, Lima JJP. Studies on retinal blood flow: II diabetic retinopathy. Arch Ophthalmol 1978;96:809-11.

18 Delori FC, Fitch KA, Feke GT, Deupree DM, Weiter JJ. Evaluation of micrometric and microdensitometric methods for measuring the width of retinal vessel images. Graefes Arch Clin Exp Ophthalmol 1988;226:393-9.

19 Grunwald JE, Riva CE, Baine J, Brucker AJ. Total retinal volumetric blood flow rate in diabetic patients with poor glycaemic control. Invest Ophthalmol Vis Sci 1992;33:356-63.

20 Kuwabara T, Cogan DG. Retinal vascular patterns VI: mural cells of the retinal capillaries. Arch Ophthalmol 1963;69:492-502.

21 Takahashi K, Brooks RA, Kanse SM, Ghatei MA, Kohner EM. Endothelin I is produced by cultured bovine retinal endothelial cells and endotheli receptors are present on associated pericytes. Diabetes 1989;38:1200-2

22 McMillan DE. The effect of diabetes on blood flow properties. Diabetes 1983;32(suppl 2):56-63.

23 Juhan I, Vague P, Buonocore $M$, Moulin JP, Jouve R, Vialettes B. Abnormalities of erythrocyte deformability and platelet aggregation in insulin-dependent diabetics corrected by insulin in vivo and in vitro. Lancet 1982;: :535-7.

24 DAMAD Study Group. Effect of aspirin alone and aspirin plus dipyridamole in early diabetic retinopathy. Diabetes $1989 ; 38: 491-8$.

25 TIMAD Study Group. Ticlopidine treatment reduces the progression of nonproliferative diabetic retinopathy. Arch Ophthalmol 1990;108:1577-83.

26 Patz A. Retinal neovascularisation: early contributions of Professor Michaelson and recent observations. Brf Ophthalmol 1984;68:42-6.

27 Milnor WR. Hemodynamics. Baltimore: Williams and Wilkins, 1989:140-1.

28 Fry DL. Certain histological and chemical responses of the vascular interface to acutely induced mechanical stress in the aorta of the dog. Circ Res 1969;24:93-108.

29 Tooke JE. Microvascular haemodynamics in diabetes mellitus. Clin Sci 1986;70:119-25

30 Burton AC. Relation of structure to function of the tissues of the walls of blood vessels. Physiol Rev 1954;34:619-42.

31 Grunwald JE, Riva CE, Brucker AJ, Sinclair SH, Petrig BL. Altered retina vascular responses to $100 \%$ oxygen breathing in diabetes mellitus. Arch Ophthalmol 1984;91:1447-52.

32 Sinclair SH, Grunwald JE, Riva CE, Braunstein SN, Nichols CW, Schwart SS. Retinal vascular autoregulation in diabetes. Ophthalmology 1982;89. 748-50.

33 Lanigan LP, Clark CV, Allawi J, Hill DW, Keen H. Responses of the retinal circulation to systemic autonomic stimulation in diabetes mellitus. Eye 1990;3:39-47.

34 Grunwald JE, Riva CE, Martin DB, Quint AR, Epstein PA. Effect of an insulin-induced decrease in blood glucose on the human diabetic retinal circulation. Ophthalmology 1987;94:1614-20.

35 Robinson F, Riva CE, Grunwald JE, Petrig BL, Sinclair SH. Retinal blood flow autoregulation in response to an acute increase in blood pressure. flow autoregulation in response to an
Invest Ophthalmol Vis $S$ ci 1986;27:722-6.

36 Knowler WC, Bennett PH, Ballintine EJ. Increased incidence of retinopath in diabetics with elevated blood pressure. $N$ Engl $\mathcal{F}$ Med 1980;302:645-50.

37 Klein R, Klein BEK, Moss SE, Davis MD, Mets DL. The Wisconsin epidemiological study of diabetic retinopathy. II. Prevalence and risk of diabetic retinopathy when age at diagnosis is less than 30 years. Arch Ophihalmol 1984;12:520-6.

38 Klein R, Klein BEK, Moss SE, Davis MD, Mets DL. The Wisconsin epidemiological study of diabetic retinopathy. III. Prevalence and risk of diabetic retinopathy when age at diagnosis is $\mathbf{3 0}$ or more years. Arch Ophthalmol 1984;12:527-32.

39 Klein BEK, Moss SE, Klein R. Effect of pregnancy on progression of diabetic retinopathy. Diabetes Care 1990;13:34-40.

40 Ogasawara H, Feke GT, Goger DG, Milbocker MT, Buzney SM. Retinal blood flow increases in normal and diabetic pregnant subjects [abstract]. Invest Ophthalmol Vis Sci 1991;34:864.

41 Behrendt T, Duane TD. Unilateral complications in diabetic retinopathy. Trans Am Acad Ophthalmol Otol 1970;74:28-32.

42 Gay AJ, Rosenbaum AL. Retinal artery pressure in asymmetric diabetic retinopathy. Arch Ophthalmol 1966;75:758-62.

43 Berkman J, Rifkin H. Unilateral nodular diabetic glomerulosclerosi (Kimmelstiel-Wilson). Report of a case. Metabolism 1973;22:715-22.

44 Brenner BM, Meyer TW, Hostetter TH. Dietary protein intake and the progressive nature of kidney disease: the role of haemodynamically mediated glomerular injury in the pathogenesis of progressive glomerula sclerosis in aging, renal ablation, and intrinsic renal disease. $N$ Engl $\mathcal{Y}$ Med 1982;307:652-9.

45 Morgenson CE. Long term antihypertensive treatment inhibiting progression of diabetic nephropathy. BMF 1982;285:685-8.

(Accepted 10 fuly 1992)

\section{ONE HUNDRED YEARS AGO}

\section{HARNESS'S ELECTRIC BELTS: IMPORTANT DECISION.}

We have received a report of a very important case tried before his Honour Judge Bacon, at the Bloomsbury County Court. The claim was for $£ 35 \mathrm{~s}$., balance of $£ 55 \mathrm{~s}$. the price of an electric belt (Harness's patent) supplied by the Medical Battery Company to Mr. Jeffery; and the defendant, by way of counter-claim, sought to have an I $\mathrm{O} U$ for $£ 35$ s. delivered up to him, and the sum of $£ 2$ cash returned to him on the following grounds: First, that he was induced to buy the electric belt through misrepresentation; and, secondly, that there was no good consideration for the contract into which he had entered with the plaintiff company. The evidence given by an electric expert was to the effect that in the electric belt sold no electricity passed through the body in any way whatever, but only along the webbing of the belt and over the skin surface, so that electrically the influence was useless. The expert witness on behalf of the Medical Battery Company, who had recommended and sold the belt, stated that prior to employment by the company he had been a salesman in an Oriental furniture shop. Judgment was given for the defendant on his counterclaim, and an order was made that the $£ 2$ he had paid be returned to him. The case is one of much importance, and we shall deal with it at greater length on a future occasion.

(BMF 1892;ii;:205.) 